\title{
Avaliação da inflamabilidade e do envelhecimento natural de compósitos de polímero verde e argila vermiculita para potencial uso na construção civil
}

\author{
Evaluation of the flammability and natural aging of green \\ polymer composites and vermiculite clay for potential \\ use as building material
}

\begin{abstract}
Felippe Fabrício dos Santos Siqueira
Tatianny Soares Alves

Renata Barbosa

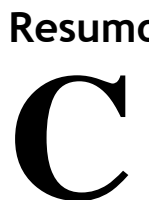

ompósitos de polietileno verde e argila vermiculita foram desenvolvidos por meio da técnica de intercalação por fusão com o objetivo de investigar seu potencial uso como material de construção. Os compósitos foram processados em uma extrusora monorosca e moldados em uma termoprensa hidráulica. Para este trabalho, foram analisadas a resistência à propagação de chamas e os efeitos do envelhecimento natural do polietileno verde e seus compósitos. Amostras foram expostas a um ensaio de degradação abiótica durante 90 dias como forma de avaliar os efeitos das condições climáticas na morfologia e nas propriedades mecânicas do material. O teste de inflamabilidade evidenciou o efeito catalítico da argila, uma vez que para todos os compósitos avaliados, a resistência à propagação de chamas foi inferior em relação ao polímero verde puro. Os efeitos do envelhecimento natural na morfologia dos materiais foram caracterizados pela transição da matriz polimérica de um aspecto dúctil para uma aparência mais frágil e o aparecimento de vazios e de fraturas internas. Em virtude disso, o desempenho mecânico dos sistemas foi diretamente afetado, como resultado de diversos tipos de degradação abiótica sofrida pelas amostras.
\end{abstract}

Palavras-chave: Polietileno verde. Argila vermiculita. Compósitos poliméricos. Propagação de chamas. Degradação abiótica. Material de construção.

${ }^{1}$ Felippe Fabrício dos Santos

Siqueira

'Universidade Federal do Piaul Teresina - PI - Brasil

${ }^{2}$ Tatianny Soares Alves ¿Universidade Federal do Piaui Teresina - PI - Brasil

${ }^{3}$ Renata Barbosa ${ }^{3}$ Universidade Federal do Piauí Teresina - PI - Brasil

Recebido em 07/08/19 Aceito em 15/12/20

\section{Abstract}

Green polyethylene and vermiculite clay composites were developed through the fusion intercalation technique with the aim of investigating their potential use as a building material. The composites were processed in a single screw extruder and molded in a hydraulic thermopress. For the purpose of this study, flame propagation resistance and the natural aging effects of green polyethylene and its composites were analyzed. The samples were exposed to the abiotic degradation test for 90 days with the aim of assessing the effects of climate conditions on the material's morphology and mechanical properties. The flammability test demonstrated the catalytic effect of the clay, since for all composites evaluated, the flame propagation resistance was inferior to that of the pure green polymer. The effects of natural aging on the morphology of the materials were characterized by the transition of the polymeric matrix from a ductile aspect to a more fragile appearance and the emergence of voids and internal fractures Hence, the mechanical performance of the systems was directly affected, as a result of several types of abiotic degradation suffered by the samples.

Keywords: Green polyethylene. Vermiculite clay. Polymer composites. Flame propagation. Weathering. Building material. 


\section{Introdução}

Os polímeros são importantes materiais em muitos setores industriais e em aplicações diárias devido a suas excelentes propriedades, permitindo a fabricação de produtos com ótimo custo-benefício. Sua gama de propriedades é tão ampla quanto à das outras classes de materiais (WANG et al., 2018; HALLIWELL, 2002). Juntamente com os metais e as cerâmicas, representam os materiais essenciais para diversos setores da economia, entre eles, o da construção civil (HALLIWELL, 2002).

A crescente demanda dos polímeros para as mais diversas aplicações em Engenharia tem resultado na busca por melhores propriedades mecânicas, térmicas, físicas e de resistência ao envelhecimento como forma de suportar condições cada vez mais rigorosas e aplicações até então inexploradas (KILIARIS; PAPASPYRIDES, 2010; FLAGA, 2000).

Atualmente, a construção civil é a segunda maior consumidora de plásticos do mundo (VASCONCELOS et al., 2020). A expansão do uso do plástico nesse setor se deve principalmente à sua resistência à corrosão, ao design diferenciado que os produtos podem adquirir, à versatilidade, à baixa condutividade térmica, à redução de custos e de tempo de obra, à diminuição dos resíduos de construção, ao baixo peso desses materiais, à economia de água no setor construtivo e à praticidade na execução de uma obra (KÖHLERHAMMER; KNIPPERS; HAMMER, 2016).

Entretanto, para algumas aplicações na construção civil, os materiais plásticos apresentam desvantagens, como elevada inflamabilidade, alta deformabilidade e envelhecimento quando exposto às condições climáticas (WANG et al., 2018; FLAGA, 2000).

A indústria da construção civil é um setor em que o comportamento dos materiais expostos ao fogo é crucial tanto para a segurança pessoal quanto para as propriedades dos materiais. Pelas crescentes exigências das normas de segurança, a inflamabilidade é uma das barreiras de utilização de alguns polímeros (ALVES et al., 2014; BARBOSA et al., 2013).

Como a maioria dos produtos orgânicos, os materiais poliméricos apresentam alta inflamabilidade, liberação de calor e produção de fumaça durante a combustão, o que limita muito sua aplicação devido ao grave risco de incêndio (WANG et al., 2018; ALVES et al., 2014; BARBOSA, et al., 2013). O aumento da resistência à propagação de chamas desses materiais é de grande importância uma vez que os plásticos representam uma grande fração incendiária nos ambientes construídos (KILIARIS; PAPASPYRIDES, 2010).

A durabilidade dos plásticos e sua resistência ao intemperismo são também alguns dos maiores entraves para seu uso como material de construção civil, principalmente para aplicações externas. O calor, a radiação solar ultravioleta, o oxigênio atmosférico, a umidade e o tipo de ambiente químico são fatores primordiais que influenciam no processo de degradação dos plásticos quando expostos ao envelhecimento natural (VASCONCELOS et al., 2020; RATANAWILAI; TANEERAT, 2018; LUCAS et al., 2008; HALLIWELL, 2002). Nesse sentido, uma simples descoloração ou uma fratura no material, resultado de seu envelhecimento natural, pode indicar sua inviabilidade de produção, uma vez que os aspectos estéticos e funcionais são determinantes na indústria da construção civil (ANDRADY et al., 1998).

O estudo da degradação e estabilização de polímeros resulta extremamente importante sob o ponto de vista científico e industrial, pois o entendimento dos mecanismos de degradação desses materiais garante maior vida útil aos produtos formados (LV et al., 2015; ZAIDI et al., 2010). Para a indústria da construção civil, esse fenômeno é de especial interesse, uma vez que os materiais de construção - que são frequentemente expostos às intempéries - devem ser estáveis por longos períodos, de forma que sejam economicamente viáveis (KÖHLER-HAMMER; KNIPPERS; HAMMER, 2016; ANDRADY et al., 1998).

São muitos os danos que o envelhecimento natural causa nos materiais poliméricos, entre eles podem ser citados: descoloração, amarelecimento, perda de brilho e opacidade dos produtos; perda de propriedades mecânicas como resistência à tração, impacto e extensibilidade; aumento da capacidade de absorver água; desenvolvimento de fragmentação e trincas internas no material; redução do peso molecular, entre outras modificações químicas (VASCONCELOS et al., 2020; WANG et al., 2018; LUCAS et al., 2008; YANG et al., 2005; QIN et al., 2003).

A tendência de aumentar o uso dos plásticos em aplicações externas, como na construção civil, tem resultado no desenvolvimento de pesquisas para a concepção de materiais com a requerida estabilidade em suas propriedades quando expostos à degradação abiótica (RATANAWILAI; TANEERAT, 2018; ANDRADY et al., 1998). A maioria dos polímeros utilizados para essa finalidade têm aditivos foto-estabilizantes e 
antioxidante para controlar o envelhecimento e assegurar um tempo de vida útil aceitável (LODI; BUENO; VILAR, 2013; ANDRADY et al., 1998).

Recentemente, os compósitos e os nanocompósitos poliméricos reforçados com argila têm recebido considerável atenção, tanto por parte dos pesquisadores quanto da indústria no campo dos polímeros. Essa nova família de materiais apresenta propriedades melhoradas por meio da adição de pequenas quantidades de argila na matriz polimérica. Entre essas propriedades, estão melhores propriedades mecânicas, estabilidade térmica, propriedades de barreira e retardação de chamas (ZHU et al., 2019; QIN et al., 2003). Além disso, essa tecnologia pode representar um avanço e uma alternativa para melhorar os problemas dos plásticos quando utilizados como materiais de construção, garantindo sua aplicabilidade.

A literatura relacionada aos compósitos e aos nanocompósitos poliméricos tem focado principalmente no processamento, nos aspectos morfológicos e nas propriedades desses materiais. Entretanto, poucos estudos evidenciam a durabilidade e a estabilidade desses materiais reforçados com cargas minerais, como as argilas, quando expostos ao envelhecimento natural, bem como ainda não está totalmente esclarecido o efeito dessas cargas na foto-oxidação de matrizes poliméricas (DINTCHEVA; AL-MALAIKA; LA MANTIA, 2009; YANG et al., 2006, 2005).

Neste sentido, este trabalho busca analisar a resistência à propagação de chamas e os efeitos do envelhecimento natural em compósitos de polietileno verde, compatibilizante polar e argila vermiculita organofilica para potencial uso como material de construção. As condições climáticas da cidade de Teresina, capital do estado do Piaú (Brasil), também foram monitoradas neste estudo.

\section{Referencial teórico}

\section{Materiais}

$\mathrm{Na}$ tentativa de desenvolver um material com menor impacto ambiental, esta pesquisa foi desenvolvida utilizando o polietileno verde de alta densidade (PEVAD) como matriz polimérica, grade SHA7260, fornecido pela Braskem. Esse polímero é produzido à base de etileno gerado pelo etanol proveniente do processamento da cana de açúcar, uma fonte natural e renovável.

Como forma de estimular e intensificar o uso de materiais regionais, foi utilizada a argila vermiculita in natura fornecida pela Mineração Pedra Lavrada (Paraíba, Brasil). Trata-se de um material silicato pertencente à subclasse dos filossilicatos, de estrutura cristalina lamelar 2:1, com potencial de aplicação em diversos segmentos, sendo frequentemente empregado na construção civil (KOTAL; BHOWMICK, 2015; UGARTE; SAMPAIO; FRANÇA, 2008). É um material natural, de fácil acesso e baixo custo que pode ser encontrado em abundância em algumas regiões do Brasil (ARAÚJO et al., 2015; UGARTE; SAMPAIO; FRANÇA, 2008).

$\mathrm{O}$ agente surfactante utilizado para modificar quimicamente a argila vermiculita foi o sal quaternário de amônio com nome comercial Praepagen $\mathrm{WB}^{\circledR}$ (cloreto de estearil dimetil amônio) e com aspecto de gel fabricado pela Clariant do Brasil.

O compatibilizante utilizado foi o polietileno de alta densidade funcionalizado com anidrido maleico (PEgMA), conhecido comercialmente como Orevac ${ }^{\circledR} 18507$ e adquirido da Arkema Innovative Chemistry.

\section{Procedimento experimental}

\section{Beneficiamento e organofilização da argila}

Inicialmente, a argila passou por um beneficiamento, processo em que foi moída por um moinho mecânico IKA A11 e passada na peneira ABNT $\mathrm{n}^{\circ} 200$ com abertura de $74 \mu \mathrm{m}$ para, posteriormente, ser organofilizada. O procedimento utilizado para sua modificação química foi o mesmo adotado por Mesquita et al. (2016).

\section{Formulação e processamento dos compósitos}

O processamento dos compósitos foi realizado por meio da técnica de intercalação por fusão, que consiste em homogeneizar o polímero, a argila organofílica e o compatibilizante por meio de equipamentos de mistura. O equipamento utilizado foi uma extrusora monorosca modelo AX-16 da AX Plásticos. 
O PEVAD, a argila vermiculita organofílica (OVMT) e o compatibilizante polar (PEgMA) foram previamente misturados por tamboreamento em diferentes proporções dos materiais, conforme descrito na Tabela 1.

Definidas as proporções, as concentrações dos sistemas foram fundidas e homogeneizadas na extrusora. O perfil de temperatura adotado para as zonas de aquecimento foi de $170{ }^{\circ} \mathrm{C}, 190{ }^{\circ} \mathrm{C}$ e $190{ }^{\circ} \mathrm{C}$, respectivamente, para as zonas 1, 2 e 3 do equipamento, com rotação da rosca mantida em $50 \mathrm{rpm}$, conforme ilustrado na Figura 1.

$\mathrm{Na}$ sequência, os sistemas foram resfriados em água a temperatura ambiente por volta de $24{ }^{\circ} \mathrm{C}$, peletizados e secos em estufa durante 4 horas a $60^{\circ} \mathrm{C}$ para posterior produção dos corpos de prova.

Os corpos de prova para os ensaios foram produzidos por meio de compressão utilizando uma termoprensa hidráulica modelo MH-08-MN da MH Equipamentos Ltda.

\section{Teste de inflamabilidade - UL94 HB}

Para analisar a resistência à chama, a taxa de queima e o desprendimento de material durante a queima das amostras, foi realizado o teste de inflamabilidade horizontal em corpos de prova normatizados pela Underwriters Laboratories (Norma UL94 (UNDERWRITERS..., 2001)). O teste foi conduzido em cinco corpos de prova para cada sistema, tanto para os compósitos quanto para a amostra referência, o polímero verde puro (PEVAD).

A taxa de queima das amostras pode ser calculada por meio da equação 1, onde $\mathrm{V}$ é a velocidade de queima ( $\mathrm{mm} / \mathrm{min})$, L é o comprimento consumido pela chama $(75 \mathrm{~mm})$ e t é o tempo necessário para que $75 \mathrm{~mm}$ do corpo de prova seja consumido pela chama:

$\mathrm{V}-60 \mathrm{~L} / \mathrm{t}$

Eq. 1

As dimensões dos corpos de prova exigidos UL94 HB são $125 \pm 5 \mathrm{~mm}$ de comprimento, $13 \pm 0,5 \mathrm{~mm}$ de largura e 3,0 $\pm 0,2 \mathrm{~mm}$ de espessura.

\section{Exposição à degradação abiótica}

O ensaio foi conduzido na cidade de Teresina, durante um período de 90 dias, entre 14 de março e 12 de junho de 2016.

Os corpos de prova produzidos foram fixados e expostos ao envelhecimento natural sobre um aparato para apoio, conforme as normas D5272-08 (AMERICAN..., 2013b) e D1435 (AMERICAN..., 2013a), com finalidade de verificar a estabilidade e a durabilidade dos PEVAD e de seus compósitos quando submetidos ao intemperismo.

Tabela 1 - Formulação dos sistemas

\begin{tabular}{c|c|c|c}
\hline \multicolumn{1}{c|}{ Sistemas } & PEVAD (\%) & PEgMA (\%) & OVMT (\%) \\
\hline PEVAD (amostra referência) & 100 & 0 & 0 \\
PEVAD/8PEgMA/1OVMT & 91 & 8 & 1 \\
PEVAD/6PEgMA/3OVMT & 91 & 6 & 3 \\
\hline
\end{tabular}

Figura 1 - llustração das zonas de aquecimento da extrusora monorosca utilizada

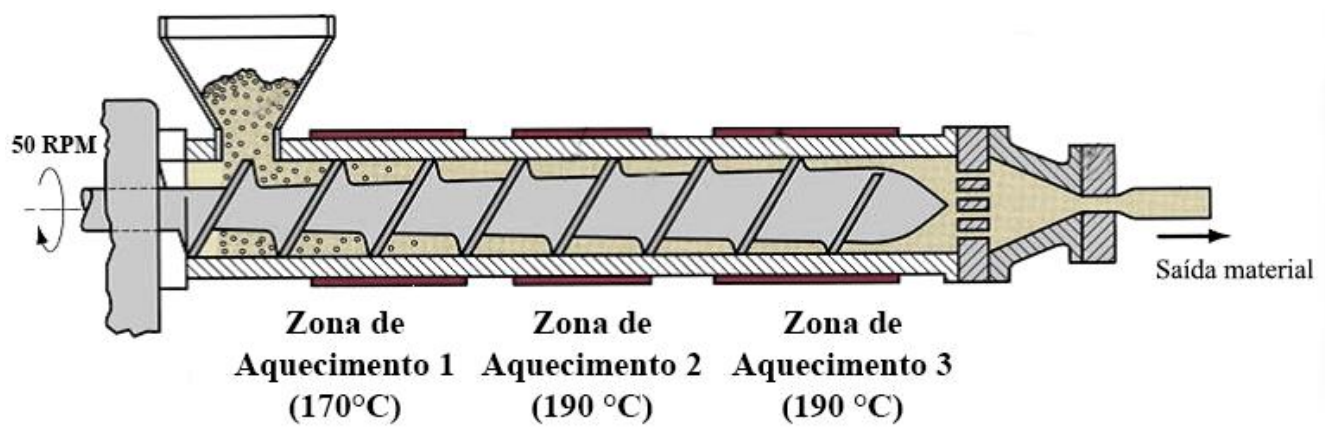


O aparato foi confeccionado em uma estrutura de madeira não tratada com uma superfície de exposição das amostras em tela de aço inox com aberturas de $15 \mathrm{~mm}$, inclinada em $5^{\circ}$ em relação à horizontal. $\mathrm{O}$ aparato foi posicionado de forma que as amostras ficassem voltadas para o Equador e que a superfície de exposição estivesse posicionada a $50 \mathrm{~cm}$ do solo. A distância entre as amostras foi de pelo menos $2 \mathrm{~cm}$. A Figura 2 apresenta o aparato de exposição utilizado no ensaio com as amostras fixadas.

A cidade de Teresina, capital do estado do Piaú, está localizada a $05^{\circ} 05^{\prime}$ de latitude sul e $42^{\circ} 48^{\prime}$ de longitude oeste, onde as altitudes máximas raramente ultrapassam $130 \mathrm{~m}$ acima do nível do mar. Teresina está situada dentro da Zona Bioclimática 7, segundo o Zoneamento Bioclimático Brasileiro e, de acordo com Köppen, tem um clima classificado como megatérmico e subúmido (Aw) com inverno seco e verão chuvoso, correspondendo ao clima tropical continental por se localizar afastada da faixa litorânea (SANTOS; SILVEIRA, 2009, 2011). O clima da cidade é marcado pelo forte contraste entre a estação seca no inverno e as precipitações concentradas no verão, com temperaturas médias anuais elevadas, variando entre 26 e $28{ }^{\circ} \mathrm{C}$ e umidade relativa média anual do ar em torno de 70\% (SANTOS; SILVEIRA, 2009, 2011; ANDRADE, 2016). Durante o primeiro semestre o clima é quente e úmido, com a média das temperaturas máximas entre 30 e $32{ }^{\circ} \mathrm{C}$ e umidade relativa média entre 75 e $85 \%$. No segundo semestre praticamente não há precipitações, e o clima é quente e seco, com temperaturas médias máximas entre 33 e $36{ }^{\circ} \mathrm{C}$ e umidade relativa do ar entre 55 e 65\% (SANTOS; SILVEIRA, 2009, 2011; ANDRADE, 2016).

Durante a exposição das amostras ao intemperismo, foram monitoradas as temperaturas diárias $\left({ }^{\circ} \mathrm{C}\right)$, a umidade relativa do ar (\%) e os níveis de precipitação $(\mathrm{mm})$ da região de exposição utilizando os dados coletados a cada hora pela estação meteorológica A312 localizada em Teresina e pertencente ao Instituto Nacional de Meteorologia (INMET). Também foi monitorado o índice de radiação ultravioleta, com dados fornecidos pelo Centro de Previsão de Tempos e Estudos Climáticos, do Instituto Nacional de Pesquisas Espaciais (CPTEC-INPE).

A distância entre a estação meteorológica e o local de exposição dos corpos de prova ao envelhecimento natural é de aproximadamente $2500 \mathrm{~m}$. O ambiente onde foi posicionado o aparato com as amostras era aberto, ao ar livre, com piso de terra com algumas vegetações rasteiras e sem nenhuma obstrução próxima (prédios, árvores etc.) que pudesse interferir nos resultados do ensaio.

\section{Avaliação da degradação abiótica}

A fim de observar os efeitos da degradação abiótica nos sistemas, foram realizadas caracterizações morfológicas por microscopia eletrônica de varredura (MEV) e ensaio mecânico de tração das amostras antes e após a exposição ao envelhecimento natural.

Figura 2 - Aparato com as amostras dos corpos de prova fixadas e expostas ao envelhecimento natural

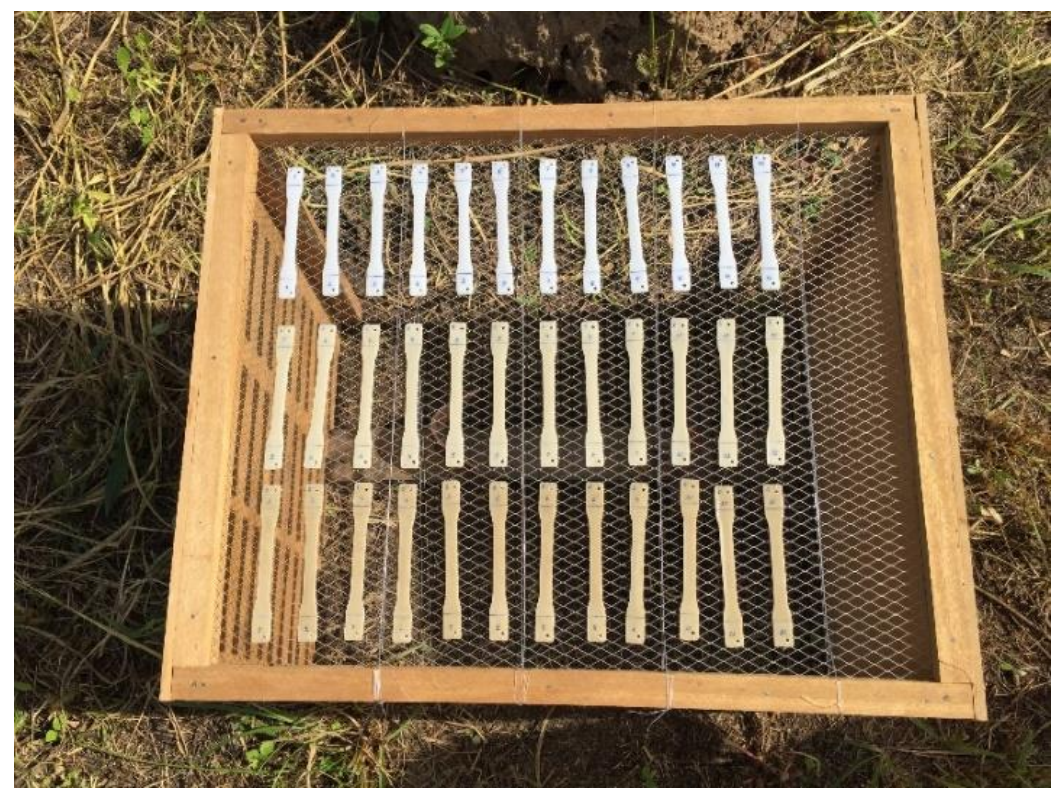


A caraterização morfológica por MEV foi conduzida para averiguar os efeitos da degradação abiótica nos sistemas após cada período de retirada. As análises foram feitas por meio do equipamento FEI Quanta FEG 250 , em alto vácuo no modo de detecção de elétrons secundários, sob tensão de $10 \mathrm{KV}$. As imagens foram obtidas em ampliações de $5000 \mathrm{X}$ para amostras oriundas de corpos de prova fraturados após o ensaio mecânico de tração, onde foram fixadas sobre stubs de latão com fita de carbono e revestidas previamente por uma fina camada de ouro utilizandoe uma metalizadora modelo Quorum Q150R.

O ensaio mecânico de tração foi realizado utilizando a máquina de ensaio universal EMIC DL 30000 N, de acordo com os parâmetros definidos pela norma D638 (AMERICAN..., 2014). O teste foi executado com seis corpos de prova para cada sistema antes da exposição ao intemperismo e repetido para as mesmas composições após serem submetidos ao envelhecimento natural em cada uma das retiradas (30 e 90 dias), com a finalidade de investigar e comparar o comportamento mecânico quando submetidos à degradação abiótica. $\mathrm{O}$ ensaio foi conduzido à temperatura ambiente e a uma velocidade de $50 \mathrm{~mm} . \mathrm{min}^{-1}$, utilizando uma célula de carga de $5 \mathrm{kN}$.

O comportamento mecânico das amostras foi analisado por meio das seguintes propriedades: módulo de elasticidade, tensão de escoamento e limite de resistência à tração (LRT).

\section{Resultados e discussão}

\section{Ensaio de inflamabilidade}

Os dados da Tabela 2 apresentam os resultados de velocidade de queima para a matriz polimérica pura e para os compósitos.

Os valores obtidos no teste mostraram que o aumento do teor de OVMT nos compósitos teve uma tendência em aumentar a velocidade de queima quando comparada com os valores obtidos pelo PEVAD.

Durante a execução do ensaio (Figura 3) verificou-se a baixa emissão de fumaça e chama relativamente alta durante a queima de todas as amostras. O desprendimento de material foi contínuo durante a combustão do PEVAD, ocorrendo o consumo de toda a amostra. Para os sistemas compostos por argila, o desprendimento de material ocorreu lentamente em forma de gotas intermitentes. Essa mudança na forma como o material se desprendeu foi atribuída à formação de uma camada rica em argila que atua como barreira e tenta inibir o gotejamento contínuo do material. Comportamento semelhante foi observado por Alves et al. (2014) em compósitos de polipropileno/argila montmorilonita organofílica.

Tabela 2 - Resultados de velocidade de queima do teste de inflamabilidade

\begin{tabular}{c|c}
\hline Sistemas & Velocidade de queima $\mathbf{( m m} / \mathbf{m i n})$ \\
\hline PEVAD (amostra referência) & $24,8 \pm 0,8$ \\
PEVAD/8PEgMA/1OVMT & $26,4 \pm 0,3$ \\
\hline
\end{tabular}

Figura 3 - Ensaio de inflamabilidade: (a) queima do PEVAD e (b) detalhe da chama na combustão de um sistema contendo argila

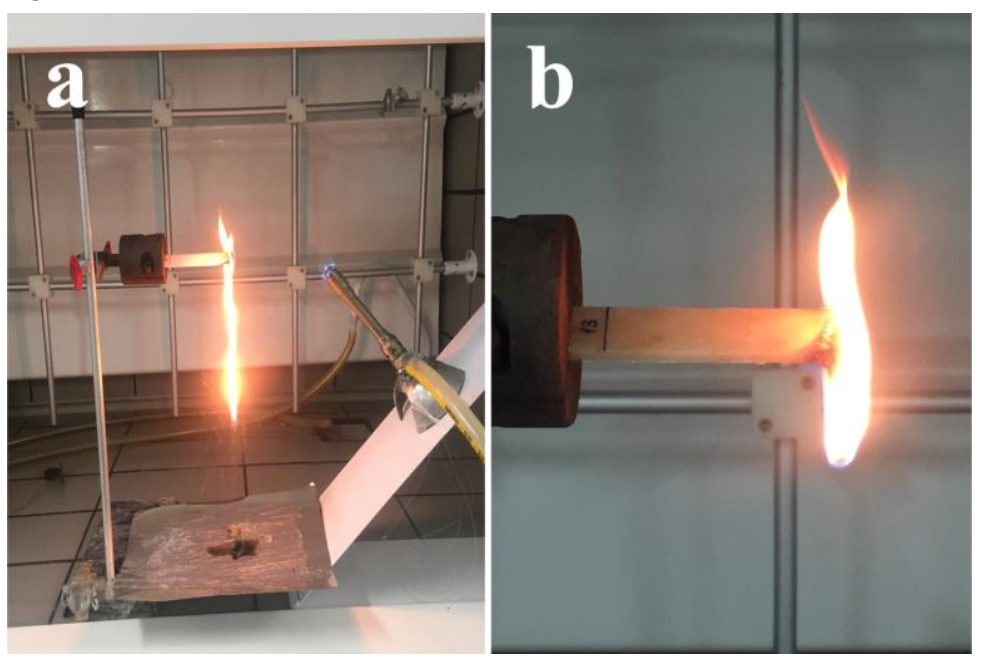


Para seu uso em construção civil, o ideal seria que os materiais apresentassem característica autoextinguível. De acordo com Alves et al. (2014), esse aspecto pode ser explicado pela baixa velocidade de queima quando em contato com o fogo e a suspensão da chama após a remoção da fonte de calor. No entanto, os resultados indicaram que os sistemas que continham argila apresentaram taxa de queima superiores à do sistema PEVAD, sendo a maior velocidade de queima registrada para o sistema PEVAD/6PEgMA/3OVMT, que foi 29,44\% superior ao valor registrado para o PEVAD.

Kiliaris e Papaspyrides (2010) relataram que, apesar de ser muito explorado o fato de que os compósitos poliméricos reforçados com argila possam melhorar as propriedades de resistência à chama quando comparados com a matriz polimérica pura, muitos artigos não levam em consideração o impacto que, em grande parte das vezes, o sal de amônio provoca nas argilas modificadas, pois o sal causa a combustão mais rápida da matriz polimérica comprometendo as propriedades de resistência à chama do material formado.

O mesmo foi observado no estudo de Zhao et al. (2005), em que o sal de amônio utilizado no processo de organofilização da argila, rico em matéria orgânica, pode atuar como um catalisador e acelerar a degradação da matriz polimérica. Zhao et al. (2005) obtiveram resultados satisfatórios ao analisar a inflamabilidade de compósitos produzidos com polietileno e argila montmorilonita organofílica, onde, ao se adicionar $3 \%$ de argila na matriz polimérica, a velocidade de queima foi reduzida em 17\%. Entretanto, quando a incorporação de argila foi de $1 \%$, a taxa de queima aumentou em torno de $30 \%$.

Barbosa et al. (2013) analisaram a taxa de queima de compósitos de polietileno de alta densidade (PEAD)/PEgMA/argila betonítica organofílica, variando a quantidade de sal de amônio no processo de organofilização para a formação dos sistemas. Foi observado que, na maioria dos sistemas com argila modificada, a velocidade de queima foi maior quando comparada com o polímero puro. Verificou-se também que, quanto maior era a quantidade de sal de amônio utilizada na organofilização da argila, menor era a resistência à propagação do fogo dos sistemas. Esse fato foi atribuído ao grande número de unidades carbonáceas presentes no sal de amônio, fazendo com que a argila não atue como um retardante de chama, mas como um agente catalisador.

Alves et al. (2014) observaram a inflamabilidade de compósitos de polipropileno/PPgMA/argila montmorilonita organofílica e constataram que, independentemente da composição dos compósitos, houve um aumento significativo da taxa de queima até $100 \%$ maior em relação ao polipropileno puro. A conclusão relatada foi que a argila acelerou a combustão da matriz polimérica devido ao efeito catalítico da argila organofílica.

\section{Condições climáticas durante a exposição à degradação abiótica}

Em março de 2016 iniciou-se o ensaio de degradação abiótica das amostras dos sistemas. No decorrer do teste, foram feitas duas retiradas para análises, sendo a primeira aos 30 dias e a segunda aos 90 dias.

A Figura 4 apresenta as variáveis climáticas monitoradas durante os 90 dias de exposição das amostras ao envelhecimento natural.

O ensaio foi conduzido durante o primeiro semestre do ano dentro do período chamado quente e úmido da cidade de Teresina. De acordo com a Figura 4a, foi observada a ocorrência de elevadas temperaturas, sendo que a temperatura máxima alcançada foi de $34,6{ }^{\circ} \mathrm{C}$, dentro do período de exposição da avaliação abiótica. No final da tarde verificou-se que as temperaturas começaram a diminuir, atingindo a temperatura mínima de $22,3{ }^{\circ} \mathrm{C}$. Durante os primeiros 30 dias, equivalente ao tempo de exposição da primeira retirada, a temperatura média para o período foi de $28,3^{\circ} \mathrm{C}$. Por sua vez, durante os 90 dias, correspondente à segunda retirada, a temperatura média registrada foi de $27,5^{\circ} \mathrm{C}$.

Analisando a variação da umidade relativa do ar durante a exposição à degradação abiótica das amostras (Figura 4b), observou-se que o período foi bastante úmido. Durante os primeiros 30 dias, relativos à primeira retirada, a umidade relativa do ar média foi de $88 \%$. Já para os 90 dias de ensaio, relativos à segunda retirada, a média foi de $77,4 \%$. Além disso, durante todo o período de monitoramento, a umidade relativa do ar atingiu valores acima de $90 \%$ em vários dias.

Os dados coletados de níveis de precipitação (Figura 4c) evidenciaram maior acúmulo de chuvas no mês de março e na primeira metade do mês de abril, em contraste com o restante do período que foi menos chuvoso. Para os primeiros 30 dias de ensaio de degradação abiótica, o acumulado foi de 212,2 mm de chuva e, para os 90 dias, o acumulado foi $272,4 \mathrm{~mm}$ de chuva. Esses resultados mostram que, após a primeira retirada das amostras, a ocorrência de chuvas diminuiu consideravelmente na região. 
Figura 4 - Condições climáticas da cidade de Teresina durante o ensaio de degradação abiótica: (a) variação da temperatura do ar, (b) variação da umidade relativa do ar e (c) variação dos níveis de precipitação

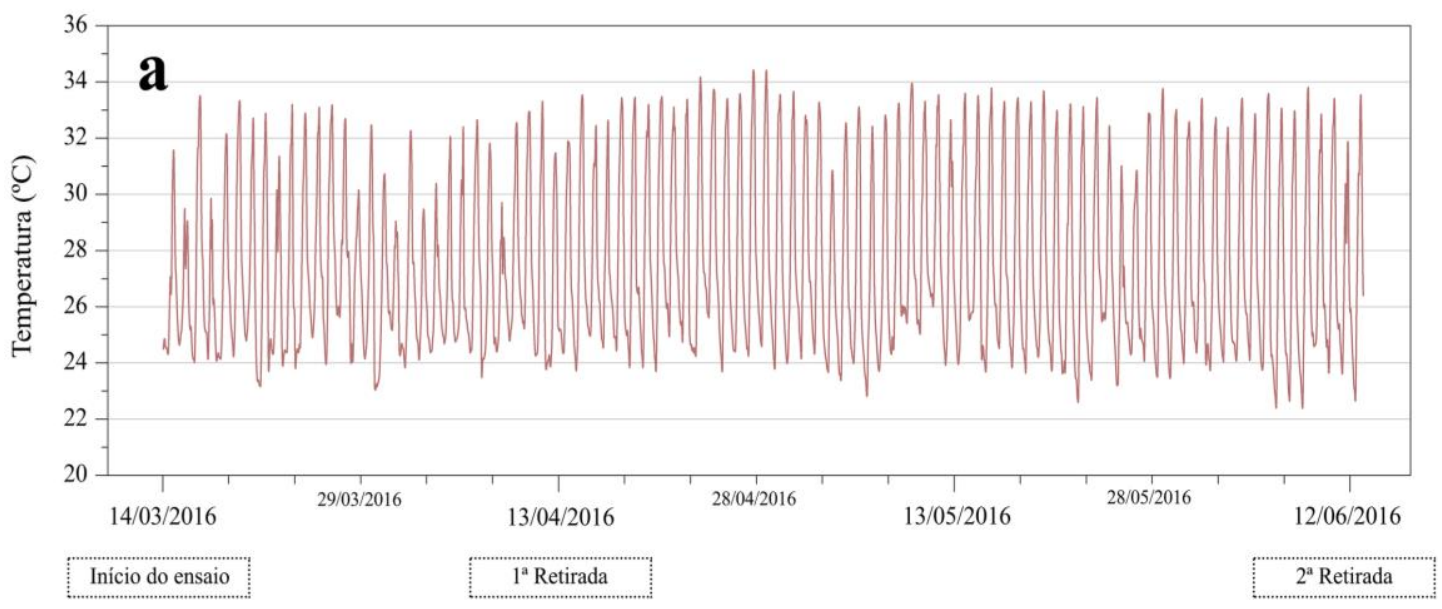

Período de exposição (90 dias)

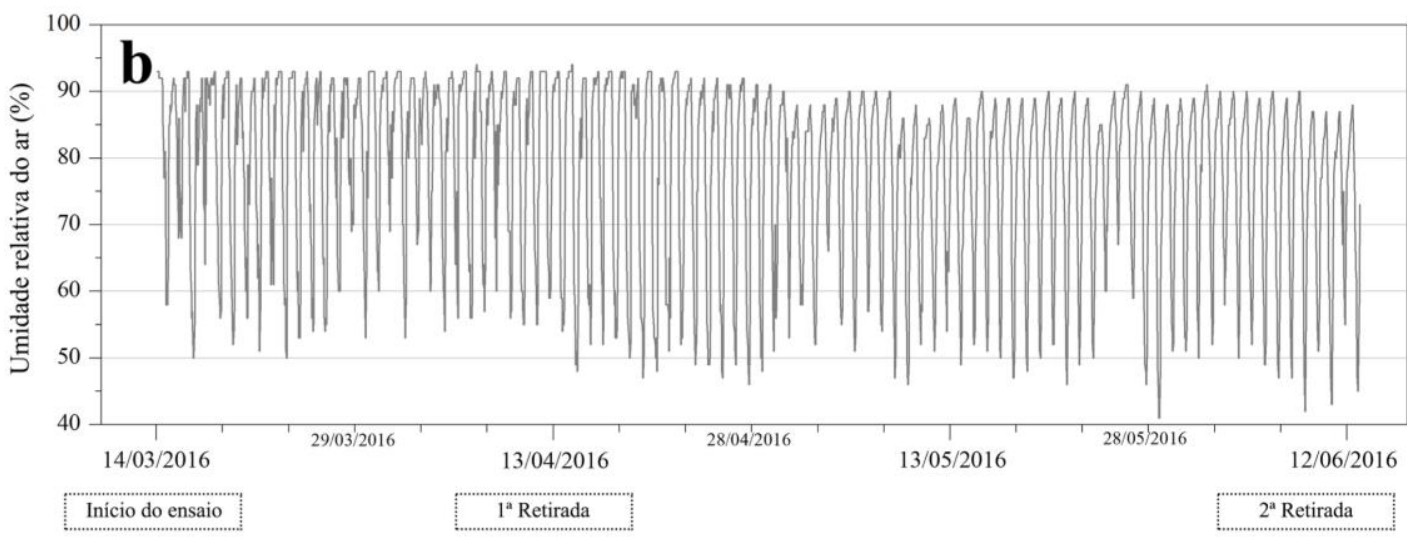

Período de exposição (90 dias)

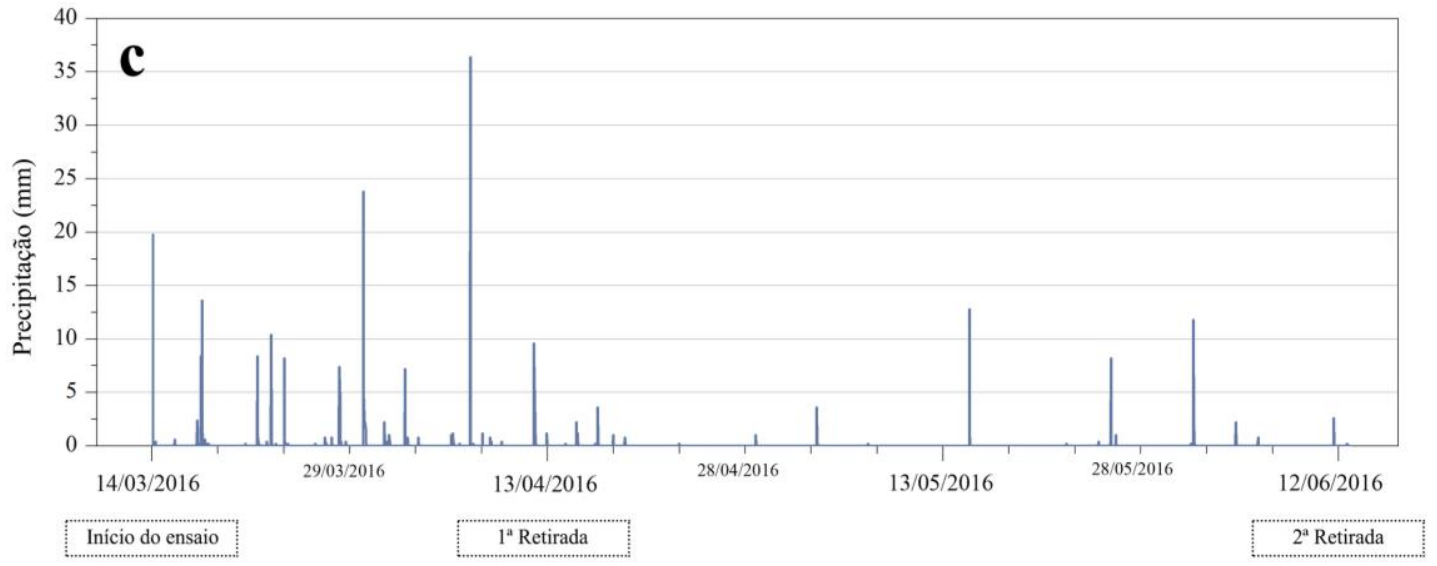

Período de exposição (90 dias)

Por estar localizada entre os trópicos e por ser caracterizada pela baixa nebulosidade, Teresina é atingida diariamente por elevadas intensidades de radiação solar. Uma forma de avaliar esse aspecto é por meio do índice ultravioleta (IUV), que é uma medida da intensidade de radiação ultravioleta (UV) incidente sobre a superfície da Terra. O IUV é agrupado em categorias de intensidade conforme mostrado na Tabela 3. 
A radiação solar pode variar de intensidade de acordo com as estações do ano, as horas do dia, a localização e os efeitos atmosféricos, como poluentes (JACQUES, 2000). Durante o ensaio de degradação abiótica, foram monitorados os IUV máximos para a cidade de Teresina, conforme valores apresentados na Figura 5.

A partir da análise da Figura 5, é possível observar que as amostras sofreram uma grande incidência de radiação UV, alcançando classificação muito alta (8-10) todos os dias de exposição. Além disso, foi possível notar que o IUV atingiu níveis extremos $(>11)$ durante os primeiros 46 dias de exposição. Durante os primeiros 30 dias de ensaio, a média do IUV máximo foi de 12,8. Por sua vez, durante os 90 dias em que as amostras foram expostas ao intemperismo, a média desse índice foi um poco menor, alcançando 10,2. Foi possível perceber também uma queda contínua na intensidade de radiação UV, isso pode ser atribuído à transição das estações do ano, pela passagem do solstício de verão, que ocorre de 21 de dezembro a 19 de março, para o equinócio de outono, que acontece entre 20 de março e 19 de junho no Hemisfério Sul, fazendo com que a radiação solar incida com menor intensidade na região.

\section{Acompanhamento da degradação abiótica por microscopia eletrônica de varredura}

Para analisar as mudanças morfológicas causadas pelos efeitos da exposição à degradação abiótica nos compósitos e na matriz polimérica, foram obtidas micrografias por MEV na superfície de fratura das amostras (Figura 6).

De um modo geral, a partir das imagens, constatou-se que a exposição ao intemperismo natural teve grande influência na morfologia dos sistemas devido aos efeitos da degradação sofrida pelas amostras.

Tabela 3 - Classificação mundial do IUV

Fonte: Instituto Nacional de Pesquisas Espaciais (2020).

\begin{tabular}{c|c}
\hline Categoria & IUV \\
\hline Baixo & $<2$ \\
Moderado & $3-5$ \\
Alto & $6-7$ \\
Muito alto & $8-10$ \\
Extremo & $>11$ \\
\hline
\end{tabular}

Figura 5 - Valores de IUV máximos para a cidade de Teresina durante o ensaio de degradação abiótica

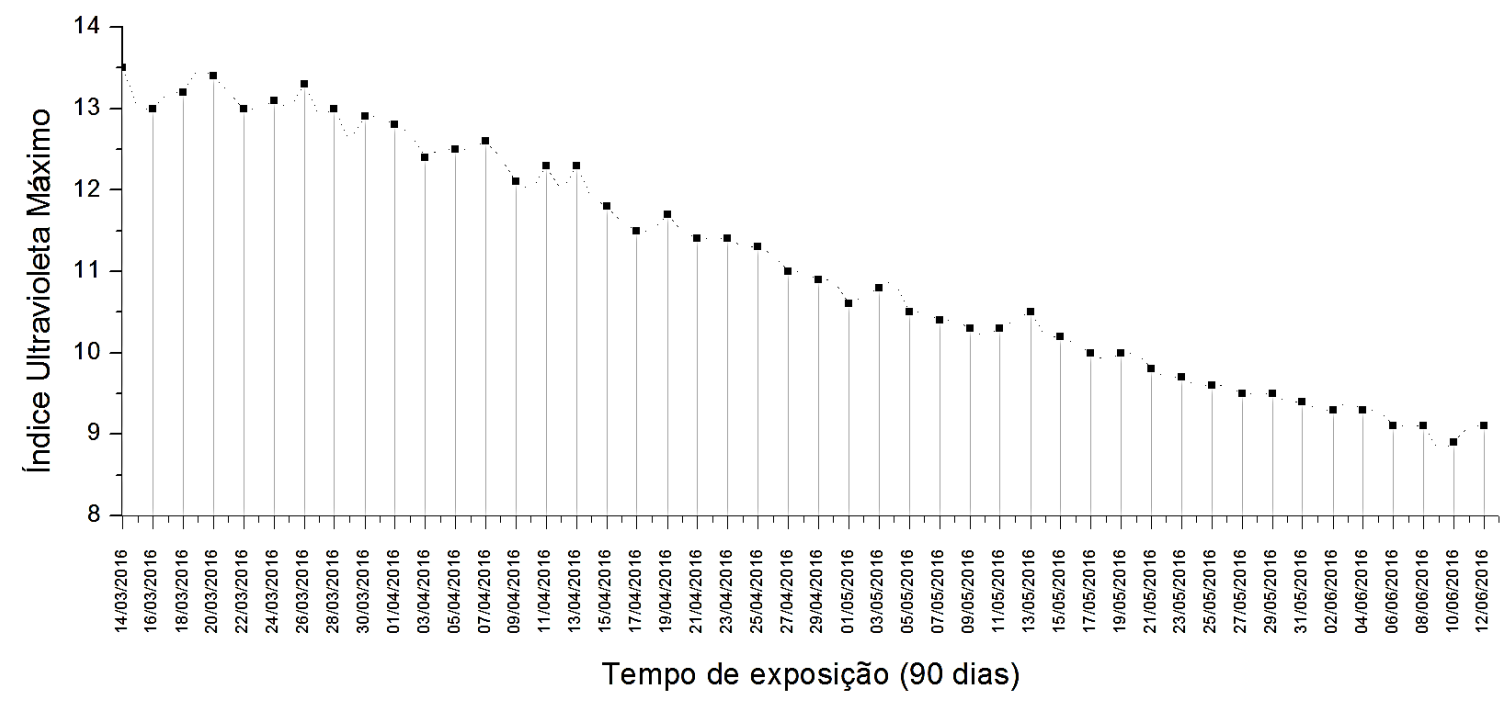


Figura 6 - Micrografias por MEV do PEVAD e seus compósitos na superfície de fratura antes e após exposição à degradação abiótica com ampliações de 5000 X: (a) PEVAD, (b) PEVAD/8PEgMA/10VMT e (c) PEVAD/6PEgMA/3OVMT; (I) sem exposição, (II) 30 dias de exposição e (III) 90 dias de exposição
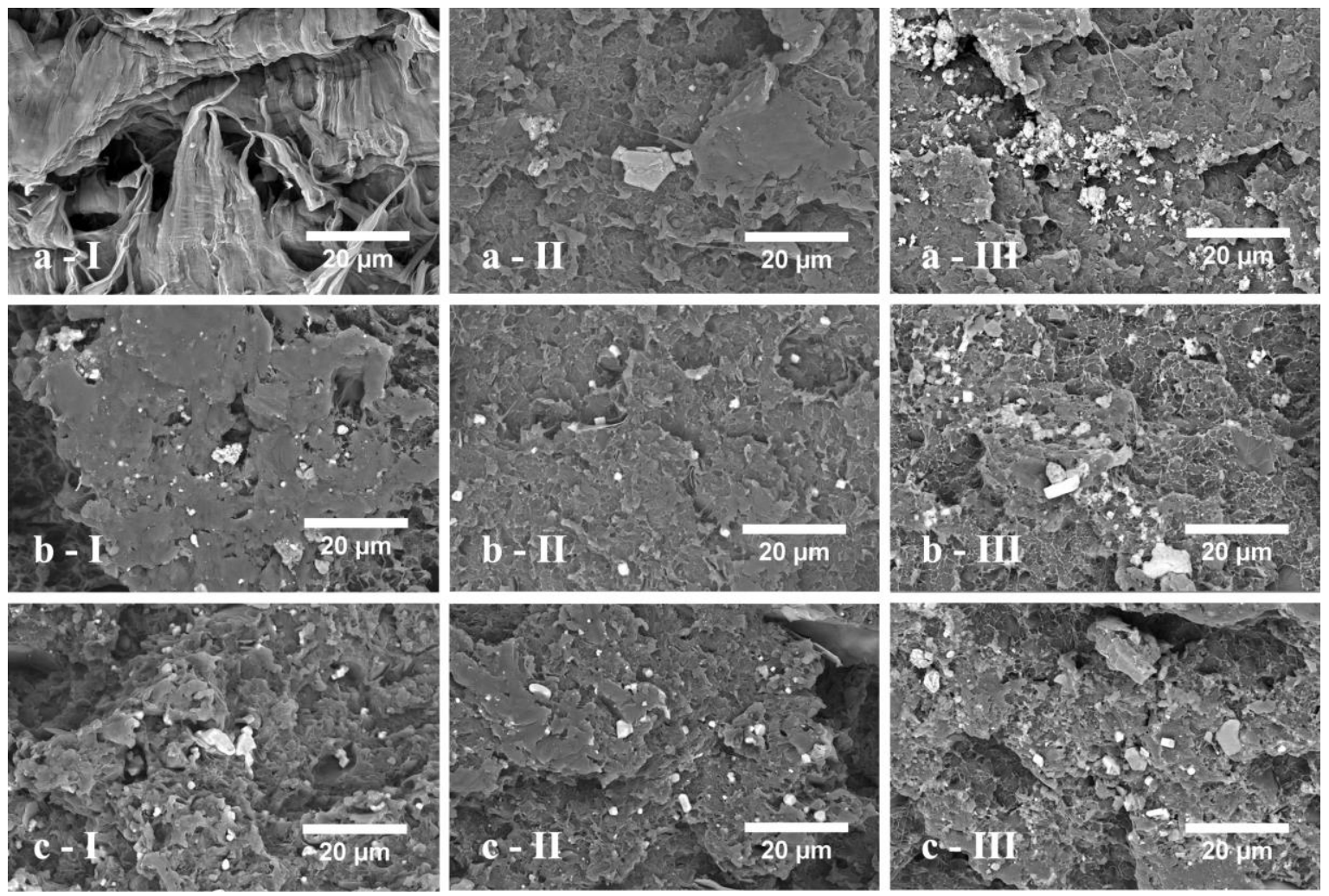

Observou-se também que houve uma mudança considerável na morfologia do PEVAD com apenas 30 dias de exposição às ações climáticas, quando comparado com a morfologia do PEVAD sem envelhecimento. A fratura passou de uma característica dúctil — caracterizada pela presença de micro fibrilas no polímero para um aspecto frágil — evidenciado por uma superfície claramente degradada em virtude de sua aparência rugosa e o aparecimento de cavidades - , sugerindo a existência de fraturas internas. Além disso, foi notado na superfície o aparecimento de partículas e regiões esbranquiçadas na matriz polimérica, em menor quantidade após 30 dias de exposição e mais numerosas após os 90 dias de ensaio.

Yakimets, Lai e Guigon (2004), ao avaliarem a influência da degradação foto-oxidativa na morfologia do polipropileno, observaram que o material passou bruscamente de uma característica dúctil para um aspecto frágil, quando exposto aos efeitos da radiação UV.

Antes de serem submetidos ao envelhecimento natural, os compósitos PEVAD/8PEgMA/1OVMT e PEVAD/6PEgMA/3OVMT exibiram um aspecto rugoso, com partículas de argilas visíveis (partes mais claras) e heterogeneamente dispersas na matriz polimérica, bem como algumas cavidades decorrentes da fraca interação entre seus constituintes. Após 30 dias de exposição às intempéries, não houve mudança significativa na morfologia dos compósitos. Aos 90 dias de exposição, foi percebido um aumento na rugosidade da superfície da fratura, bem como o aparecimento de partículas e aumento de regiões esbranquiçadas, vistas também nas micrografias do PEVAD, sendo mais evidentes no sistema PEVAD/8PEgMA/1OVMT.

Segundo Yang et al. (2005), essas partículas e regiões esbranquiçadas também foram observadas pelos autores quando analisaram compósitos de PEAD reforçados com diferentes cargas inorgânicas. Eles consideraram que essas partículas eram referentes aos esferulitos de PEVAD, formados na região amorfa do polímero e expostos na superfície de fratura.

Degradações foto-oxidativas nas matrizes poliméricas iniciam principalmente na região amorfa do material em detrimento à região cristalina, uma vez que esta última apresenta maior densidade, o que previne a difusão de $\mathrm{O}_{2}$. Em virtude disso, degradações em regiões amorfas formam partículas de esferulitos expostas na superfície do polímero (YANG et al., 2005). 
Os vazios observados nas imagens morfológicas dos sistemas envelhecidos são indício da perda de fragmentos oriundos de cisões, ramificações e/ou reticulações de cadeia, como consequência de degradações foto-oxidativas (YANG et al., 2005) ou pelas cisões hidrolíticas nessas cadeias causadas pela penetração de moléculas de água decorrentes das precipitações.

De acordo com Zaidi et al. (2010) e Montagna e Santana (2012), essas mudanças observadas na morfologia das amostras podem ser atribuídas às reações termo e foto-oxidativas que levaram à formação de radicais altamente reativos como ligações duplas vinílicas, grupos carbonilas, anidridos e hidroperóxidos. Esses fotoprodutos são resultados de diversos mecanismos químicos oriundos de quebra, ramificação e/ou reticulação de cadeias moleculares da matriz polimérica (YANG et al. 2005).

As severas condições climáticas da cidade de Teresina impostas às amostras durante o ensaio foram decisivas ao catalisarem essas reações. A partir das micrografias por MEV, foi possível perceber mudanças morfológicas no PEVAD e em seus compósitos em virtude dos efeitos da degradação abiótica. Entretanto, não foi possível mensurar com exatidão em quais sistemas esses efeitos foram mais proeminentes ou como a argila influenciou nos processos foto-degradantes. Esses aspectos serão confirmados posteriormente por meio da análise das propriedades mecânicas dos sistemas, antes e após a exposição das amostras ao intemperismo natural.

\section{Acompanhamento da degradação abiótica por meio das propriedades mecânicas}

Os resultados das propriedades mecânicas obtidas do ensaio de tração dos sistemas, antes e após a exposição ao envelhecimento natural, estão apresentados na Tabela 4.

As condições climáticas afetaram diretamente o desempenho mecânico dos sistemas. Segundo Yakimets, Lai e Guigon (2004), longas exposições ao intemperismo natural provocaram abruptas modificações na tensão de escoamento, na resistência à tração, no módulo elástico, na viscosidade e na elongação de materiais poliméricos. De uma maneira geral, os resultados obtidos confirmaram esse fato ao apontarem uma significativa redução das propriedades mecânicas dos sistemas após a exposição das amostras ao intemperismo natural.

A Figura 7 apresenta os resultados para o módulo de elasticidade PEVAD e seus compósitos antes e após exposição ao envelhecimento natural.

Antes de serem expostos ao intemperismo, os compósitos apresentaram módulo de elasticidade superiores ao do sistema PEVAD. Decorridos os períodos de exposição à degradação abiótica (30 e 90 dias), observouse uma redução significativa no módulo elástico nos três sistemas analisados.

O PEVAD teve sua rigidez reduzida em aproximadamente $13 \%$ após 30 dias sob envelhecimento natural e em aproximadamente $28 \%$ após 90 dias de exposição. Percebeu-se também que as reduções na rigidez sofrida pelo PEVAD nos primeiros 30 dias de ensaio foram mais intensas, chegando a valores acima de 50\% do total da rigidez perdida aos 90 dias de ensaio.

Tabela 4 - Propriedades mecânicas do PEVAD e seus compósitos antes e após a exposição ao envelhecimento natural

\begin{tabular}{c|c|c|c|c}
\hline Sistemas & $\begin{array}{c}\text { Tempo de } \\
\text { exposição (dias) }\end{array}$ & $\begin{array}{c}\text { Módulo de } \\
\text { elasticidade } \\
\text { (MPa) }\end{array}$ & $\begin{array}{c}\text { Tensão de } \\
\text { escoamento } \\
\text { (MPa) }\end{array}$ & $\begin{array}{c}\text { Limite de } \\
\text { resistência à } \\
\text { Tração (MPa) }\end{array}$ \\
\hline \multirow{2}{*}{ PEVAD (amostra referência) } & 0 & $468,0 \pm 38,0$ & $15,1 \pm 1,0$ & $26,6 \pm 0,6$ \\
& 30 & $408,0 \pm 22,1$ & $12,2 \pm 0,3$ & $23,2 \pm 0,4$ \\
& 90 & $337,7 \pm 6,1$ & $10,6 \pm 1,2$ & $14,9 \pm 0,3$ \\
\hline \multirow{2}{*}{ PEVAD/8PEgMA/1OVMT } & 0 & $503,1 \pm 8,2$ & $13,0 \pm 0,3$ & $25,6 \pm 0,4$ \\
& 30 & $419,2 \pm 8,6$ & $11,8 \pm 0,5$ & $20,0 \pm 0,4$ \\
PEVAD/6PEgMA/3OVMT & 90 & $369,4 \pm 22,1$ & $11,5 \pm 0,5$ & $12,6 \pm 0,6$ \\
\hline & 0 & $517,0 \pm 10,1$ & $13,2 \pm 0,5$ & $24,0 \pm 1,3$ \\
& 30 & $454,1 \pm 36,6$ & $11,0 \pm 0,6$ & $19,3 \pm 0,6$ \\
\hline
\end{tabular}


Figura 7 - Módulo de elasticidade PEVAD e seus compósitos, antes e após exposição ao envelhecimento natural

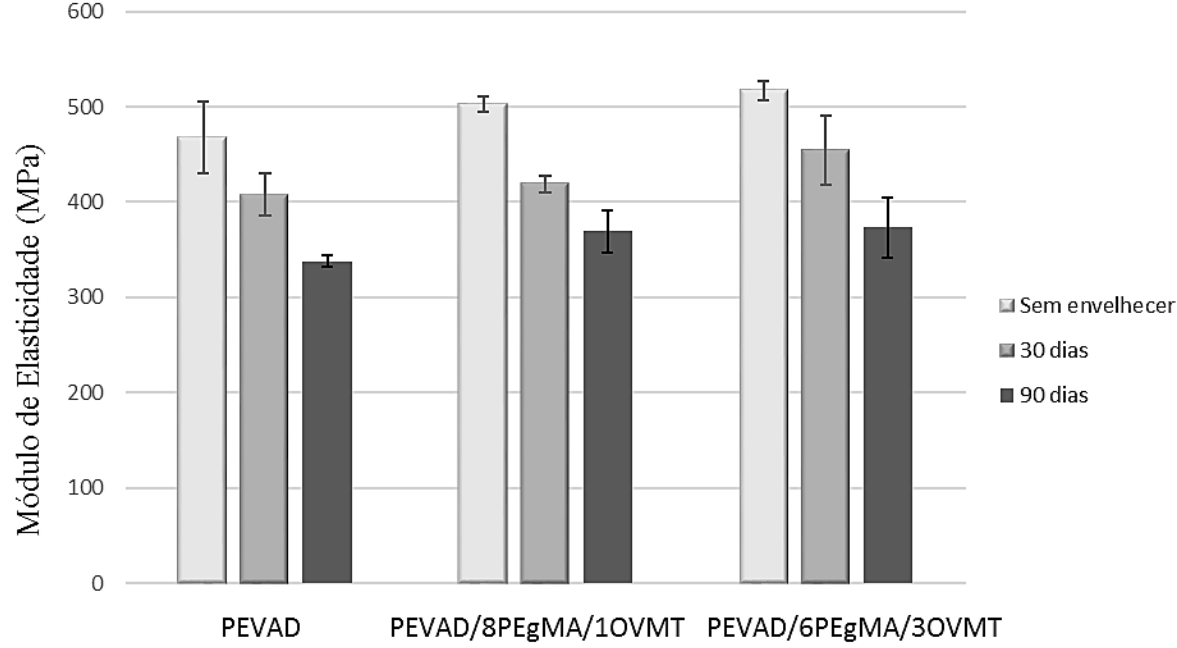

Os sistemas PEVAD/8PEgMA/1OVMT e PEVAD/6PEgMA/3OVMT obtiveram desempenhos semelhantes aos observados para o PEVAD, uma vez que foi verificado que os compósitos também sofreram redução no módulo de elasticidade em torno de $28 \%$ após 90 dias de exposição, quando comparados com as amostras não expostas ao envelhecimento natural. A partir dessas informações, foi possível inferir que a argila vermiculita e o compatibilizante polar não apresentaram nenhum efeito sobre a degradação abiótica com relação ao módulo de elasticidade.

Catto, Almeida e Santana (2014) investigaram as propriedades mecânicas de compósitos de PP/EVA/pó de madeira submetidos ao intemperismo e observaram que as condições climáticas afetaram no resultado, diminuindo gradualmente o módulo de elasticidade conforme maior foi o tempo de exposição.

Yakimets, Lai e Guigon (2004) afirmaram que a redução no módulo de elasticidade decorre da presença de trincas internas causadas por degradações foto-oxidativas em virtude da ação do tempo, o que tornou o material mais quebradiço. Essas trincas propagam-se no material, aumentando a superfície exposta à radiação UV e facilitando a difusão de $\mathrm{O}_{2}$ em regiões mais profundas. Por esse motivo, é possível confirmar as suspeitas da presença de fraturas internas observadas nas análises morfológicas por MEV.

A Figura 8 apresenta os resultados de tensão de escoamento do PEVAD e seus compósitos antes e após exposição ao envelhecimento natural.

Sem a ação do intemperismo, os resultados apontaram que a tensão de escoamento do PEVAD é maior do que a observada para os compósitos que têm sua capacidade de se deformar elasticamente comprometida devido à presença da argila. Entretanto, depois de expostos ao envelhecimento natural, a diferença entre as tensões de escoamento do PEVAD e de seus compósitos foram minimizadas, ao ponto de, nos sistemas PEVAD/8PEgMA/1OVMT e PEVAD/6PEgMA/3OVMT, os valores apresentados serem superiores aos do sistema PEVAD, quando expostos durante 90 dias à degradação abiótica.

Após 30 dias de exposição, as amostras sofreram uma redução da tensão de escoamento de aproximadamente $19,5 \% ; \quad 9 \%$ e $17 \%$ para os sistemas PEVAD, PEVAD/8PEgMA/1OVMT e PEVAD/6PEgMA/3OVMT, respectivamente. Porém, depois de 90 dias de exposição ao intemperismo, verificou-se uma queda acentuada da tensão de escoamento para o sistema PEVAD, que foi de aproximadamente $30 \%$, contra $11,5 \%$ e $17 \%$ para os sistemas de compósitos PEVAD/8PEgMA/1OVMT e PEVAD/6PEgMA/3OVMT, respectivamente.

Constatou-se que os efeitos da degradação abiótica foram menores nos compósitos, uma vez que apresentaram perdas de tensão de escoamento inferiores à observada para o PEVAD. Esse fato pode estar relacionado à elevada umidade relativa do ar na cidade de Teresina e à ocorrência de chuvas na região no período do ensaio de degradação abiótica. Nessas condições, a água absorvida pela superfície degradada do material, em contato com a argila nos compósitos, passou a exercer a função de um plastificante natural. Segundo Ammala et al. (2011), esse fato pode ser facilitado pela mudança de comportamento hidrofóbico 
para hidrofilico do polietileno, permitindo que fragmentos do polímero absorvam água quando expostos à foto-oxidação.

Os LRT do PEVAD e seus compósitos estão apresentados na Figura 9.

Os resultados de LRT para os sistemas, sem os efeitos do intemperismo, indicaram que a resistência à tração do sistema PEVAD foi maior que a encontrada para os sistemas dos compósitos. Com 30 dias de exposição ao intemperismo, o PEVAD sofreu uma redução de aproximadamente $12,6 \%$, frente a $22 \%$ para o PEVAD/8PEgMA/1OVMT e 19\% para o PEVAD/6PEgMA/3OVMT. Após 90 dias de exposição, essas reduções foram muito acentuadas: acima de $40 \%$ para os três sistemas analisados, aproximando de $51 \%$ para o nanocompósito com $1 \%$ de argila.

A combinação de temperaturas elevadas, que alcançaram quase $35{ }^{\circ} \mathrm{C}$, precipitações acumuladas de $272,4 \mathrm{~mm}$, umidade relativa do ar acima de $90 \%$ e intensidade de radiação UV em níveis extremos, foram preponderantes para os danos causados nas propriedades mecânicas dos sistemas.

De acordo com Catto, Almeida e Santana (2014), esses resultados evidenciaram que as amostras dos sistemas foram submetidas a diversos tipos de degradação, tais como foto-oxidativa, térmica, hidrolítica e outras, que afetaram as propriedades mecânicas e fragilizaram o material.

Figura 8 - Tensão de escoamento PEVAD e seus compósitos, antes e após exposição ao envelhecimento natural

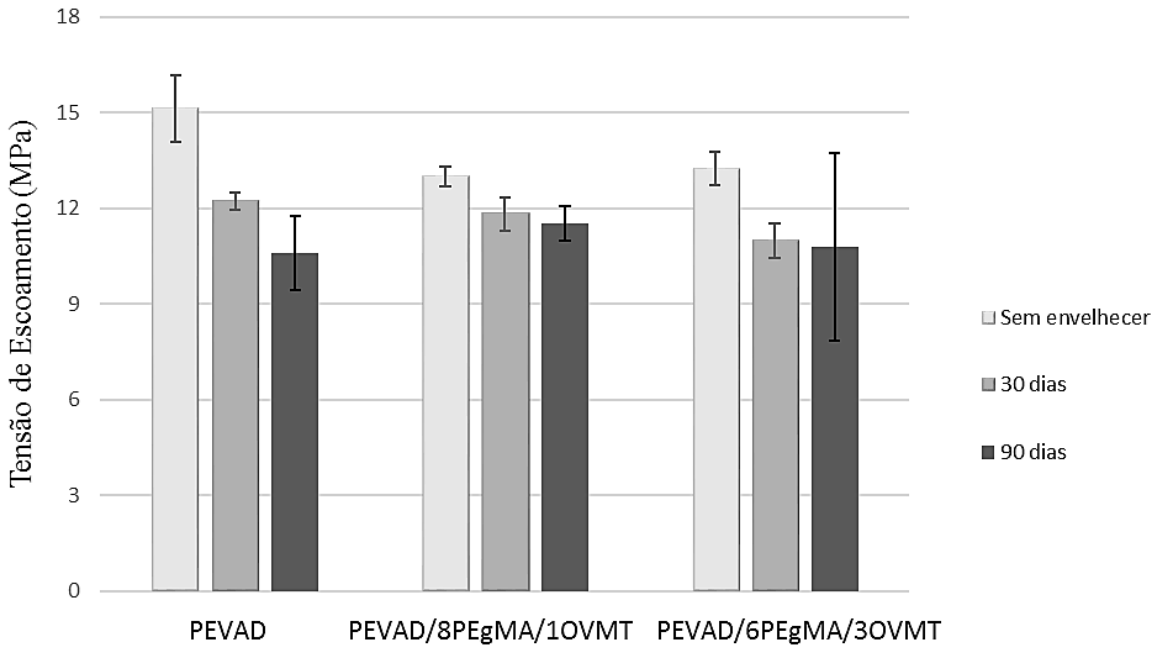

Figura 9 - LRT do PEVAD e de seus compósitos, antes e após exposição ao envelhecimento natural

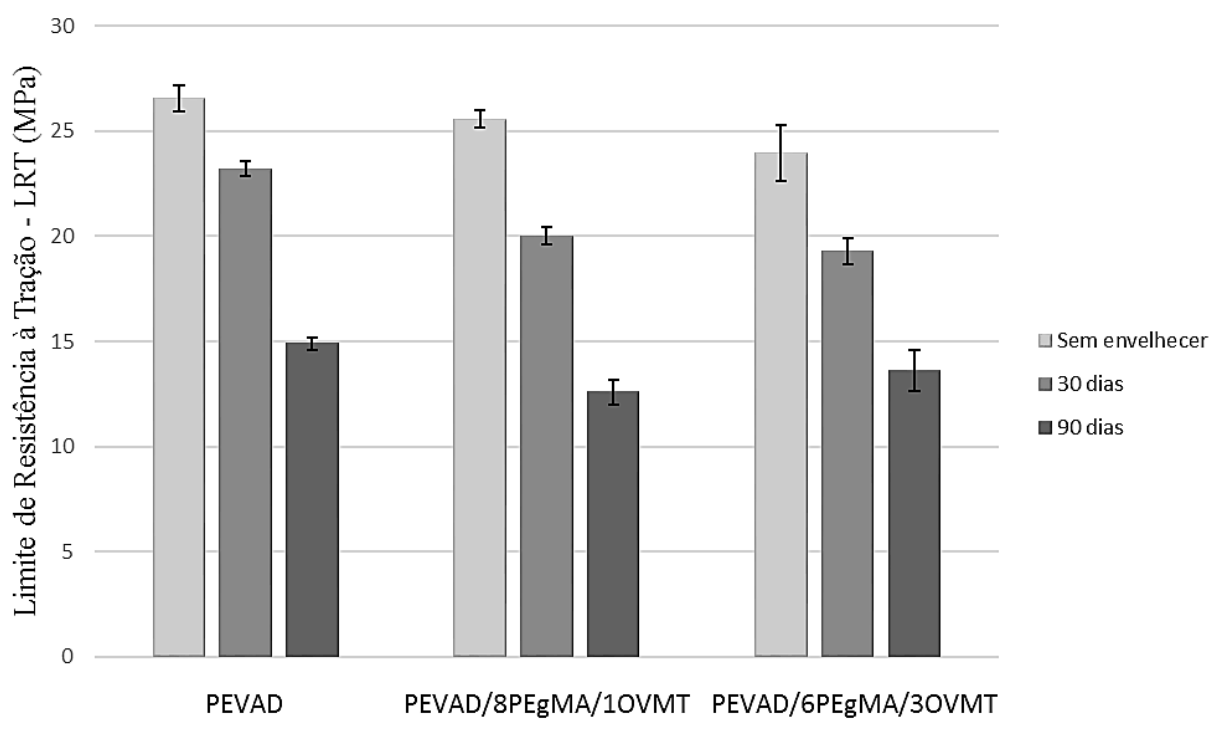


Sob condições de umidade, as moléculas de água penetram nas amostras, desencadeando reações de hidrólise, e os resultados são ligações interfaciais mais fracas e adesões entre as cadeias poliméricas comprometidas, as quais reduzem potencialmente a resistência mecânica do material (RIDZUAN et al., 2016; JACQUES, 2000).

Pelas análises do comportamento mecânico dos sistemas, não foi possível obter uma conclusão plausível sobre o feito da OVMT e do agente compatibilizante na degradação abiótica das amostras devido à heterogeneidade dos resultados nas propriedades mecânicas. Entretanto, alguns trabalhos atestam que compósitos poliméricos reforçados com argila degradam mais rápido que o polímero puro quando submetidos a processos foto-oxidativos. A relativa instabilidade desses materiais ao envelhecimento natural, ativado por radiação UV, pode ser atribuída à presença de metais de transição como o ferro na composição das argilas, que podem acelerar processos foto-oxidativos, ao caráter catalítico das impurezas da argila organofílica e/ou à degradação dos cátions alquilamônio presentes no sal quaternário de amônio durante o processo de organofilização (ZAIDI et al., 2010; DINTCHEVA; AL-MALAIKA; LA MANTIA, 2009; KUMANAYAKA; PARTHASARATHY; JOLLANDS, 2010; QIN et al., 2003).

\section{Conclusão}

O polietileno verde, o compatibilizante polar e a OVMT foram combinados para produzir compósitos para possíveis aplicações como material de construção civil. Os materiais foram processados por meio da técnica de intercalação por fusão, utilizando-se uma extrusora monorosca para misturar e homogeneizar os constituintes e uma termoprensa hidráulica para moldar os corpos de prova.

Os resultados do teste de inflamabilidade indicaram o efeito catalítico dos compósitos dada a presença do sal de amônio que é rico em matéria orgânica. Em todos os sistemas que continham argila, a capacidade de resistência à propagação de chama foi inferior à da amostra referência (PEVAD).

As amostras foram expostas ao ensaio de envelhecimento natural por um período de 90 dias como forma de avaliar os efeitos das condições climáticas na morfologia e nas propriedades mecânicas do material. Durante o ensaio foram monitoradas as temperaturas di árias, a umidade relativa do ar, os níveis de precipitação e IUV. O período de exposição foi caracterizado por elevadas temperaturas, alta umidade relativa do ar, vários dias chuvosos e intensidade de radiação atingindo níveis extremos. A combinação desses fatores provocou modificações na estrutura do material, afetando diretamente suas propriedades.

$\mathrm{O}$ efeito do envelhecimento natural na morfologia do material caracterizou-se pela transição de uma matriz polimérica de aspecto dúctil para uma aparência mais frágil, pelo aparecimento de vazios e fraturas internas e pela formação de esferulitos de PEVAD. Essas características são indícios de modificações físicas e químicas causadas por degradações foto-oxidativas e hidrolíticas no material.

Em virtude disso, o desempenho mecânico dos sistemas foi diretamente afetado, ocorrendo perda das propriedades mecânicas após exposição das amostras ao intemperismo natural. $\mathrm{O}$ módulo de elasticidade sofreu redução em todos os sistemas após 90 dias de envelhecimento natural. Os sistemas também sofreram redução na tensão de escoamento, porém com maiores efeitos no PEVAD. O LRT foi a propriedade mecânica mais afetada pelas ações do intemperismo. Isso é resultado de diversas categorias de degradação abiótica (foto-oxidativa, térmica, hidrolítica, entre outras) sofrida pelas amostras, que corroboraram os danos causados nas propriedades mecânicas dos sistemas.

Apesar de as propriedades não terem sido satisfatórias na maior parte para os materiais analisados, os compósitos poliméricos reforçados com argila podem representar uma evoluão e inovação dos materiais de construção civil. Entretanto, seu processamento, composição química e propriedades para este fim devem ser continuamente estudadas.

\section{Referências}

ALVES, T. S. et al. Inflamabilidade de nanocompósitos de polipropileno/argila organofílica. Polímeros, v. 24, n. 3, p. 183-189, 2014.

AMERICAN SOCIETY FOR TESTING MATERIALS. D1435: standard practice for outdoor weathering of plastics. West Conshohocken, 2013a.

AMERICAN SOCIETY FOR TESTING MATERIALS. D5272-08: standard practice for outdoor exposure testing of photodegradable plastics. West Conshohocken, $2013 \mathrm{~b}$. 
AMERICAN SOCIETY FOR TESTING MATERIALS. D638: standard test method for tensile properties of plastics. West Conshohocken, 2014.

AMMALA, A. et al. An overview of degradable and biodegradable polyolefins. Polymer Degradation and Stability, v. 36, p. 1015-1049, 2011.

ANDRADE, C. S. Teresina e clima: indissociabilidades no estudo da cidade. Revista Equador, v. 5, n. 3, p. 398-420, 2016.

ANDRADY, A. L. et al. Effects of increased solar ultraviolet radiation on materials. Journal of Photochemistry and Photobiology B: Biology, v. 46, p. 96-103, 1998.

ARAÚJO, R. J. et al. Influência da argila vermiculita brasileira na biodegradação de filmes de PHB.

Polímeros, v. 25, p. 483-491, 2015.

BARBOSA, R. et al. Flammability and morphology of HDPE/clay nanocomposites. Journal of Thermal Analysis and Calorimetry, v. 115, p. 627-634, 2013.

CATTO, A. L.; ALMEIDA, S. H.; SANTANA, R. M. C. Abiotic degradation of recycled polymer/wood composites exposed to outdoor applications. Journal of Materials Science and Engineering A, v. 11, p. 321-329, 2014

DINTCHEVA, N. T.; AL-MALAIKA, S.; LA MANTIA, F.P. Effect of extrusion and photo-oxidation on polyethylene/clay nanocomposites. Polymer Degradation and Stability, v. 94, p. 1571-1588, 2009.

FLAGA, K. Advances in materials applied in civil engineering. Journal of Materials Processing Technology, v. 106, p. 173-183, 2000.

HALLiWELL, S. M. Polymers in building and construction. Rapra Review Reports, v. 13, n. 10, p. 3-27, 2002.

INSTITUTO NACIONAL DE PESQUISAS ESPACIAIS. [UV]. Disponível em: https://satelite.cptec.inpe.br/uv/. Acesso em: 20 dez. 2020.

JACQUES, L. F. E. Accelerated and outdoor/natural exposure testing of coatings. Progress in Polymer Science, v. 25, p. 1337-1362, 2000.

KILIARIS, P.; PAPASPYRIDES, C. D. Polymer/layered silicate (clay) nanocomposites: an overview of flame retardancy. Progress in Polymer Science, v. 35, p. 902-958, 2010.

KÖHLER-HAMMER, C.; KNIPPERS, J.; HAMMER, M. R. Bio-based plastics for building facades. StartUp Creation, p. 329-346, 2016.

KOTAL, M.; BHOWMICK, A. K. Polymer nanocomposites from modified clays: recent advances and challenges. Progress in Polymer Science, v. 51, p. 127-187, 2015.

KUMANAYAKA, T. O.; PARTHASARATHY, R.; JOLLANDS, M. Accelerating effect of montmorillonite on oxidative degradation of polyethylene nanocomposites. Polymer Degradation and Stability, v. 95, p. 672-676, 2010

LODI, P. C.; BUENO, B. S.; VILAR, O. M. The effects of weathering exposure on the physical, mechanical, and thermal properties of high-density polyethylene and poly (vinyl chloride). Materials Research, v. 16, p. 1331-1335, 2013.

LUCAS, N. et al. Polymer biodegradation: Mechanisms and estimation techniques. Chemosphere, v. 73, p. 429-442, 2008.

LV, Y. et al. Outdoor and accelerated laboratory weathering of polypropylene: a comparison and correlation study. Polymer Degradation and Stability, v. 112, p. 145-159, 2015.

MESQUITA, P. J. P. et al. Thermal evaluation of PHB/PP-g-MA blends and PHB/PP-g-MA/vermiculite bionanocomposites after biodegradation test. Polymer Engineering and Science, v. 56, p. 555-560, 2016.

MONTAGNA, L. S.; SANTANA, R. M. C. Influência da radiação solar na degradação do polipropileno. In: CONGRESSO INTERNACIONAL DE TECNOLOGIAS PARA O MEIO AMBIENTE, 3., Bento Gonçalves, 2012. Anais [...] Bento Gonçalves, 2012.

QIN, H. et al. Photo-oxidative degradation of polyethylene/montmorillonite nanocomposite. Polymer Degradation and Stability, v. 81, p. 497-500, 2003. 
RATANAWILAI, T.; TANEERAT, K. Alternative polymeric matrices for wood-plastic composites: effects on mechanical properties and resistance to natural weathering. Construction and Building Materials, v. 172, p. 349-357, 2018.

RIDZUAN, M. J. et al. Moisture absorption and mechanical degradation of hybrid Pennisetum purpureum/glass-epoxy composites. Composite Structures, v. 141, p. 110-116, 2016.

SANTOS, F. F.; SILVEIRA A. L. R. C. Análise da eficiência energética de edifícios da Universidade Federal do Piauí. In: ENCONTRO NACIONAL DE CONFORTO NO AMBIENTE CONSTRUÍDO, 10., Natal, 2009. Anais [.... Natal: ANTAC, 2009.

SANTOS, F. F.; SILVEIRA A. L. R. C. Desempenho térmico de lajes de concreto expostas à radiação solar em Teresina-PI. In: ENCONTRO NACIONAL DE CONFORTO NO AMBIENTE CONSTRUÍDO, 11. Búzios, 2011. Anais [...] Búzios, ANTAC, 2011.

UGARTE, J. F. O; SAMPAIO, J. A; FRANÇA, S. C. A. Vermiculita. In: LUZ, A. B; LINS, F. A. F. Rochas e minerais industriais: usos e especificações. 2. ed. Rio de Janeiro: CETEM/MCT, 2008.

UNDERWRITERS LABORATORIES. UL-94: test for flammability of plastic materials for parts in devices and appliances. Northbrook: Underwriters Laboratories, 2001.

VASCONCELOS, G. C. M. S. et al. Effects of weathering on mechanical and morphological properties cork filled green polyethylene eco-composites. Polímeros, v. 30, n. 1, 2020.

WANG, B. et al. Monitoring the degradation of physical properties and fire hazards of high-impact polystyrene composite with different ageing time in natural environments. Journal of Hazardous Materials, v. 352, p. 92-100, 2018.

YAKIMETS, I.; LAI, D.; GUIGON, M. Effect of photo-oxidation cracks on behaviour of thick polypropylene samples. Polymer Degradation and Stability, v. 86, p. 59-67, 2004.

YANG, R. et al. Effects of inorganic fillers on the natural photo-oxidation. Polymer Degradation and Stability, v. 88, p. 333-340, 2005.

YANG, R. et al. Thermal oxidation products and kinetics of polyethylene composites. Polymer Degradation and Stability, v. 91, p. 1651-1657, 2006.

ZAIDI, L. et al. Effect of natural weather on the structure and properties of polylactide/Cloisite 30B nanocomposites. Polymer Degradation and Stability, v. 95, p. 1751-1758, 2010.

ZHAO, C. et al. Mechanical, thermal and flammability properties of polyethylene/clay nanocomposites. Polymer Degradation and Stability, v. 87, p. 183-189, 2005.

ZHU, T. T. et al. Exfoliation of montmorillonite and related properties of clay/Polymer nanocomposites. Applied Clay Science, v. 169, p. 48-66, 2019.

\title{
Felippe Fabrício dos Santos Siqueira
}

Programa de Pós Graduação em Ciência e Engenharia dos Materiais | Universidade Federal do Piauí | Bairro Ininga, s/n | Teresina - PI Brasil | CEP 64049-550 | E-mail: f.fabricio@hotmail.com

\section{Tatianny Soares Alves}

Programa de Pós Graduação em Ciência e Engenharia dos Materiais | Universidade Federal do Piauí | E-mail: tsaeng3@yahoo.com.br

Renata Barbosa

Programa de Pós Graduação em Ciência e Engenharia dos Materiais | Universidade Federal do Piauí | E-mail: rrenatabarbosa@yahoo.com

\author{
Ambiente Construído \\ Revista da Associação Nacional de Tecnologia do Ambiente Construído \\ Av. Osvaldo Aranha, $99-3^{\circ}$ andar, Centro \\ Porto Alegre - RS - Brasil \\ CEP $90035-190$ \\ Telefone: +55 (51) 3308-4084 \\ Fax: +55 (51) 3308-4054 \\ www.seer.ufrgs.br/ambienteconstruido \\ E-mail: ambienteconstruido@ufrgs.br
}

